\title{
Identifying evolutionarily conserved genes in the dietary restriction response using bioinformatics and subsequent testing in Caenorhabditis elegans
}

\author{
Andreas Hanno Ludewig • Maja Klapper • \\ Frank Döring
}

Received: 14 October 2013/Accepted: 16 November 2013/Published online: 6 December 2013

(C) Springer-Verlag Berlin Heidelberg 2013

\begin{abstract}
Dietary restriction (DR) increases life span, health span and resistance to stress in a wide range of organisms. Work from a large number of laboratories has revealed evolutionarily conserved mechanisms that mediate the DR response. Here, we analyzed the genome-wide gene expression profiles of Caenorhabditis elegans under DR versus ad libitum conditions. Using the Ortho2ExpressMatrix tool, we searched for C. elegans orthologs of mouse genes that have been shown to be differentially expressed under DR conditions in nearly 600 experiments. Based on our bioinformatic approaches, we obtained 189 DRresponsive genes, and 45 of these are highly conserved from worm to man. Subsequent testing of sixteen genes that are up-regulated under DR identified eight genes that abolish the DR-induced resistance to heat stress in $C$. elegans. Further analyses revealed that $f k b-4, d o d-22$ and $i k b-l$ genes also abolish increased life span in response to DR. The identified genes that are necessary for the DR response are sensitive to certain stress signals such as metabolic perturbances (dod-22, fkb-4 and $n h r-85$ ), DNA damage (ikb-l), heat shock (hsp-12.6) and cancer-like overgrowth (prk-2 and $t s p-15$ ). We propose that most of the DR-responsive genes identified are components of the recently discovered cellular surveillance-activated detoxification and defenses pathway, which is, among others, important for the survival of organisms in times of food deprivation.
\end{abstract}

Electronic supplementary material The online version of this article (doi:10.1007/s12263-013-0363-5) contains supplementary material, which is available to authorized users.

A. H. Ludewig · M. Klapper · F. Döring ( $\square)$

Department of Molecular Prevention,

Institute of Human Nutrition and Food Science, University of

Kiel, Heinrich-Hecht-Platz 10, 24118 Kiel, Germany

e-mail: sek@molprev.uni-kiel.de; hal@molprev.uni-kiel.de
Keywords Dietary restriction - Functional ortholog · Life span $\cdot$ Heat stress $\cdot$ C. elegans

\section{Introduction}

In the past decades, nutritional science has increasingly shifted from an expert niche to the central focus of molecular genetics, biochemistry, bioinformatics and medical research as important interconnections between the diet and widespread diseases such as cancer, stroke, neurodegenerative diseases and cardiovascular diseases became apparent (Hirabayashi et al. 2013; Hariri and Thibault 2010; Kahn et al. 2006; Van Gaal et al. 2006). Even more importantly, dietary restriction (DR) increases life span, health span and resistance to environmental stress in a wide range of organisms (Mair and Dillin 2008). DR is defined as a significant reduction in energy and macronutrient intake in the absence of malnutrition (Weindruch et al. 1988). A large number of laboratories are involved in unraveling the molecular mechanisms that mediate the DR response. The TOR/AMPK, insulin, sirtuin and autophagy pathways are important for this response (Kenyon 2010). Notably, many components of these pathways were first identified in model organisms such as Caenorhabditis elegans and have subsequently been confirmed as important in higher organisms, including humans (Kenyon 2010; Kenyon et al. 1993; Tissenbaum and Guarente 2001; Mair and Dillin 2008).

Over the past 30 years, the increasing application of high-throughput technologies (HTP) within the field of molecular genetic research has shifted the focus from studying the activity of single genes, proteins and pathways to the level of whole genomes, transcriptomes and metabolomes, thus introducing the "-omics" era of life science 
(Szewczyk et al. 2006; Smith and Petrenko 1997; Li et al. 2004; Pungaliya et al. 2009). As a consequence, huge amounts of data derived from various HTP approaches studying a large number of species, tissues and diseases are being assembled. Nevertheless, adequately dissecting those data to generate relevant scientific information still appears to be very challenging. In the present study, we introduce a comprehensive meta-analysis of microarray data acquired in the model organisms C. elegans and the mouse, under DR versus ad libitum (AL) conditions. The major aim of the study was the identification of evolutionarily conserved genes in the DR response. Therefore, we combined bioinformatic approaches with functional assays in C. elegans.

\section{Materials and methods}

Data sets and databases

Five microarray data sets were generated in our laboratory [(Palgunow et al. 2012); Klapper et al. unpublished]. Two microarray data sets were obtained from the Gene Expression Omnibus (Barrett et al. 2009) and Array Express (Parkinson et al. 2009) databases. Common databases and tools such as Wormbase, InterPro, NCBI GenBank, KEGG pathways, Pfam, Gene Ontology, DAVID, a tissue-specific expression prediction tool (Chikina et al. 2009) and the Ortho2Express Matrix program (Meinel et al. 2011) were used.

Nematode strains and dietary restriction protocol

The following $C$. elegans strains were used:

Wild-type N2, cpr-2(ok2833), hsp-12.6(ok1077), odr10(ky225), ftn-1(ok3625), fkb-4(ok240), ikb-1(nr2027), C05D11.7b aka dpy-5(e907) I, sEx16156, nhr-85(ok2051), prk-2(ok3069), tsp-15(sv15), dod-22(ok1918), F35E12.8 (ok2220), dod-17(ok2387), dod-24(ok2629), C33A11.1 (ok3681) and sup-12(ok1843). Mutant strains were obtained from the Caenorhabditis Genetics Center (Minneapolis, MN, USA). The DR protocol was recently established in our group (Palgunow et al. 2012). Briefly, standard NGM medium without bactopeptone was used to induce DR on 90-mm-diameter agar plates. E. coli OP50 bacteria were grown at $37{ }^{\circ} \mathrm{C}$ in DYT medium until they reached an optical density $(600 \mathrm{~nm})$ of 1.5 . Subsequently, the bacterial suspension was concentrated or diluted in M9 buffer, resulting in a series of bacterial suspensions ranging from $\mathrm{OD}_{600 \mathrm{~nm}} 0.3$ to 6.0 . In total, $250 \mu \mathrm{l}$ of each suspension was seeded per plate. For the ad libitum condition, the plates used were standard NGM plates that were seeded with $250 \mu \mathrm{l}$. coli with an $\mathrm{OD}_{600 \mathrm{~nm}}$ of 1.5. Plates were incubated at $37{ }^{\circ} \mathrm{C}$ overnight.
Heat stress assays

The experimental plates were 35-mm-diameter NGM plates seeded with OP50. Late L4-stage worms were picked from synchronized NGM plates and transferred (15-25 worms per plate) to experimental plates. After completion of development to adults at $20{ }^{\circ} \mathrm{C}(16 \mathrm{~h})$, plates were incubated at $35^{\circ} \mathrm{C}$. After $6 \mathrm{~h}$ of heat exposure, survival was scored hourly by assessing touch-provoked movement until all worms had died. At least four plates were used for each condition; all experiments were carried out at least twice at two different times. The SPSS version 19 (IBM) statistical analysis package was used for all thermotolerance statistics. $P$ values were calculated using the log-rank (Mantel-Cox) method.

\section{Life span assays}

A total of 100 hermaphrodite N2 worms were picked from synchronized plates, transferred to 35-mm-diameter NGM plates seeded with OP50 and then allowed to lay eggs for $60 \mathrm{~min}$. Thirty eggs were picked from each plate and transferred to fresh plates seeded with OP50 bacteria. Worms were transferred every 2 days until they stopped reproducing. Subsequently, they were transferred every 7 days until death. Animals were scored as dead if they failed to respond to a tip on the head and tail with a platinum wire. Worms with internal hatching, exploding worms or worms that left the plate were excluded.

\section{Results}

Identification of evolutionarily conserved genes that are differentially expressed in response to dietary restriction

To identify genes that are differentially expressed in response to DR, we used five microarray-based gene expression data sets generated in our laboratory and tested DR conditions versus AL conditions in C. elegans (Palgunow et al. 2012; Klapper unpublished). In these experiments, early-larval-stage L4 animals, late L4 worms and adults were exposed to mild or severe DR. In addition, we used two available data sets (GSE6057 and GSE 9682) that were derived from experiments with mixed-stage wild-type worms grown in liquid minimal axenic medium versus worms grown on full medium (Szewczyk et al. 2006) and animals exposed to intermittent fasting or ad libitum food intake (Honjoh et al. 2009). We selected genes that exhibited consistent up- or down-regulation in response to DR in at least five out of seven data sets (Fig. 1a, S2). This approach yielded 157 DR-responsive genes (Table S2). As 

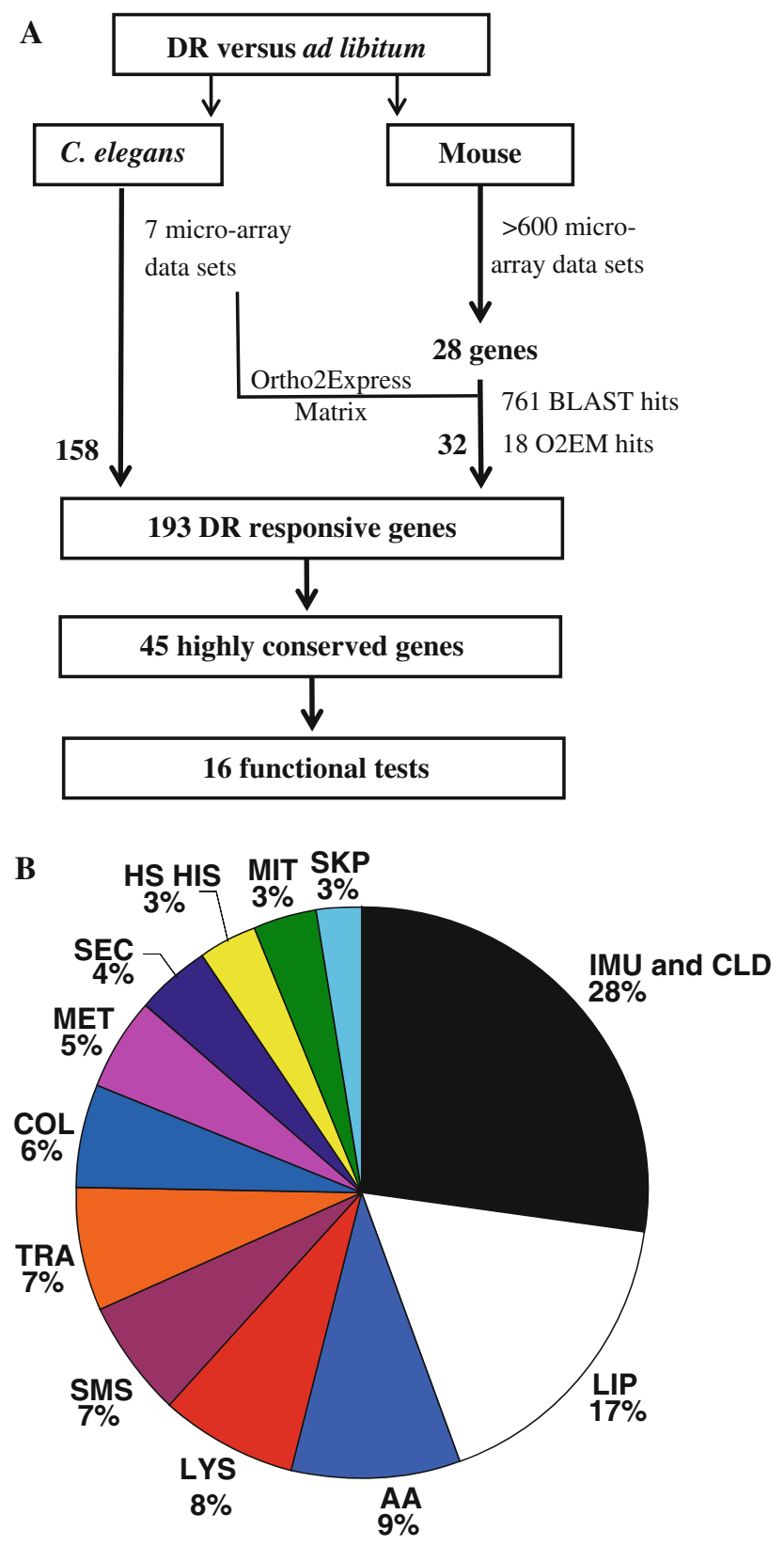

Fig. 1 a Schematic representation of the bioinformatic approaches to identify and classify DR-responsive genes. Data mining of DRspecific regulated genes arisen in microarray assays in mouse and $C$. elegans reveals a list of 44 highly conserved genes; b functional allocation of DR-responsive genes into different classes. IMU innate immunity, CLD, $A A$ amino acid metabolism, LIP lipid homeostasis, SMS small signaling molecules, HSP HIS heat shock proteins or histones, TRA transport processes MIT mitochondrial function, $N A D$ NADH, MAP MAPK, SKP skp-1, LYS lysis, SEC secreted proteins, $C O L$ collagens, $M E T$ metallothionein metabolism

a second approach, we searched for functional C. elegans orthologs of 28 mouse genes that have been shown to be regulated under DR in nearly 600 experiments (Swindell 2008; Table S1). We used the Ortho2Express Matrix tool (Meinel et al. 2011) to identify functional orthologs in the two species (Fig. 1a). We found no orthologs in C. elegans for ten mouse genes, suggesting that these might be evolutionarily "modern" genes (Fig. 1a). For 18 mouse genes, we found 32 C. elegans functional orthologs. The homology and functional domains of their encoded proteins were further analyzed (Figure S2).

We obtained 189 DR-responsive genes from our bioinformatic approaches (Table S2-S4). Of these, 75 were upregulated and 114 were down-regulated (Fig. 1). For 106 genes, the function is not known or the predicted function has not been analyzed in depth. Of these, 54 genes are nematode specific, while 45 genes are evolutionarily conserved (Table S2, Fig. 1). Thirty-three genes have been described in the context of DR (Table S3). For 45 genes, we found clear functional annotations, but these genes have not been analyzed under DR yet (Table S4). Sequence conservation of the 189 genes identified was further analyzed with public databases. Ultimately, 20 and 25 genes are up-regulated and down-regulated, respectively, in response to DR (Table 1, Fig. 1) and are highly conserved from worm to man. Of the up-regulated genes, 16 were subsequently tested in C. elegans.

Allocation of identified genes into functional clusters and networks

The DAVID tools were used to allocate the identified genes into functional gene clusters. The 25 down-regulated genes assemble into five clusters (Table S6). Cluster 1 ( $p c p-3$, pcp-2, K10B2.2, asp-2, T18H9.2, Y40D12A.2 and Y16B4A.2) contains genes involved in proteolysis and lysosomal activity. Cluster 2 (C49C3.9, F40F4.6, T25C12.3, T25C12.5, clec-41, C48B4.9, ZK899.2, hpo-34, F57F4.4, col-101, C29F3.7b and F40F4.6) encompasses genes involved in the positive regulation of growth. Of note, the genes in these clusters are down-regulated under DR. This result agrees with previous studies showing decreased growth under DR (Tain et al. 2008). Cluster 3 (col-80, col-8, col-184, col-143 and col-19) exclusively contains genes that encode collagen isoforms. The genes in cluster 4 (ugt-22, ugt-26 and ugt-41) encode UDP-glucuronosyl/UDP-glucosyl transferases. When we analyzed the function and functional domains of these genes, we found that an extraordinarily high number (27) of down-regulated genes are members of the CUB-like domain protein family (Table S5, S10). Furthermore, we found groups of genes that are involved in lipid homeostasis (20), amino acid metabolism (11), synthesis of small signaling molecules (8) and innate immunity (5) (Fig. 1b, Table S7).

Next, we analyzed the identified genes with respect to functional interconnections. We noticed a general high interconnectivity between genes that are involved in amino acid metabolism (F57F5.1), fatty acid desaturation 
Table 1 Twenty evolutionarily conserved gene (a) up- and (b) down-regulated in response to dietary restriction
All assigned genes have been similarly regulated under DR in at least five out of seven approaches

Genes showing up in more than one class have been annotated to the most obvious category

$I M U$ innate immunity, CLD, FO functional ortholog of mouse genes, $A A$ amino acid metabolism, LIP lipid homeostasis, $A N D$ other functions, $S M S$ small signaling molecules, HSP HIS heat shock proteins or histones, TRA transport processes $M I T$ mitochondrial function, $N A D$ NADH, MAP MAPK, SKP skp1, LYS lysis, SEC secreted proteins, $C O L$ collagens, MET metallothionein metabolism

a Gene name

b Gene ID

c Functional classification

d Maximal fold change DR/AL in microarray assays

e Most prominent (predicted) function

f $\%$ Homology to the closest human ortholog

$\mathrm{g}$ Appearance in literature, without

h Interactors in this study/total interactors

\begin{tabular}{|c|c|c|c|c|c|c|c|c|}
\hline & Symbol $^{\mathrm{a}}$ & $\mathrm{ID}^{\mathrm{b}}$ & $\mathrm{CL}^{\mathrm{c}}$ & $\mathrm{FC}^{\mathrm{d}}$ & Function $^{\mathrm{e}}$ & $\mathrm{H}^{\mathrm{f}}$ & $L^{g}$ & $\mathrm{I}^{\mathrm{h}}$ \\
\hline \multirow[t]{20}{*}{ (a) } & droe- 8 & ZC196.6 & UNK & 6,3 & Growth & 61 & 0 & - \\
\hline & droe-1 & F21F3.3 & AA & 27,2 & Amino acid methylation & 73 & 1 & - \\
\hline & droe -5 & T09B9.2 & TRA & 3,6 & Transporter protein & 88 & 0 & 1 \\
\hline & tsp-15 & F53B6.1 & FO & 1,5 & Tetraspanin family & 86 & 6 & 0 \\
\hline & $f t n-1$ & C54F6.14 & GA & 56 & Ferritin heavy chain homologs & 99 & 17 & 0.08 \\
\hline & $f k b-4$ & ZC455.10 & FO & 3,3 & Regulated by DAF-2 & 85 & 6 & 1 \\
\hline & - & C05D11.7 & $\mathrm{FO}$ & 1,6 & Lipid metabolic process & 33 & 2 & 0 \\
\hline & sup-12 & $\mathrm{T} 22 \mathrm{~B} 2.4 \mathrm{a}$ & $\mathrm{FO}$ & 2,1 & Cytoskeleton & 85 & 11 & 0.72 \\
\hline & cpr-2 & F36D3.9 & AA & 200 & Cysteine protease related & 97 & 3 & 0.04 \\
\hline & $m t l-1$ & & MET & 146 & Metallothionein & 68 & 47 & 0.05 \\
\hline & - & C33A11.1 & $\mathrm{FO}$ & 2,1 & Protein binding & 31 & 0 & 0 \\
\hline & hsp-12.6 & F38E11.2 & HSP & 31,7 & Heat shock protein & 72 & 14 & 0.72 \\
\hline & $n h r-85$ & W05B5.3a & $\mathrm{FO}$ & 1,8 & Dauer formation & 59 & 9 & 0.1 \\
\hline & $i k b-1$ & $\mathrm{C} 04 \mathrm{~F} 12.3$ & $\mathrm{FO}$ & 5,9 & Immune response & 36 & 11 & 0 \\
\hline & prk-1 & C06E8.3a & $\mathrm{FO}$ & 1,9 & & 46 & 9 & 0.05 \\
\hline & ins-35 & K02E2.4 & SMS & 10,0 & Insulin-related peptide & 35 & 1 & 0 \\
\hline & odr -10 & C53B7.5 & AND & 5,7 & G-protein-coupled receptor & 20 & 85 & 0.05 \\
\hline & droe -4 & F58E10.7 & AND & 5,2 & Amyloid beta protein binding & 30 & 0 & 0.63 \\
\hline & nlp-35 & C33A12.2 & SMS & 8,2 & Neuropeptide-like protein & 23 & 3 & 0 \\
\hline & ugt-36 & F09G2.6 & LIP & 2,4 & UDP-glucuronosyl transferase & 95 & 0 & 0 \\
\hline \multirow[t]{25}{*}{ (b) } & $d r d-1$ & F49E12.9 & MIT & 4,9 & Sterol desaturase & 99 & 0 & 0.67 \\
\hline & $g b a-4$ & Y4C6B.6 & LYS & 5,5 & Beta-glucocerebrosidase & 99 & 0 & - \\
\hline & vit-1 & K09F5.2 & LIP & 49,5 & Vitellogenin protein & 67 & 17 & 0.38 \\
\hline & $d r d-3$ & W07B8.1 & AA & 6,8 & Cysteine proteinase & 98 & 0 & 0.1 \\
\hline & $d r d-50$ & F49F1.1 & LYS & 16,3 & Secreted surface protein & 66 & 2 & - \\
\hline & folt-2 & F37B4.7 & TRA & 23,8 & Folate transporter family & 96 & 1 & 0.33 \\
\hline & $s w t-6$ & R10D12.9 & LIP & 7,9 & Sugar efflux transporter & 68 & 0 & 0 \\
\hline & $m s i 3 p$ & C30C11.4 & HSP & 1,8 & Heat shock protein & 99 & 5 & - \\
\hline & $d r d-51$ & C48B4.1 & LIP & 5,3 & Nhr-49 ard starv sensing & 98 & 2 & 0.1 \\
\hline & $d r d-2$ & F40F4.6 & MAP & 16,7 & Wnt inhibitory factor 1 & 7 & 0 & 0.06 \\
\hline & $d r d-4$ & F57F5.1 & AA & 11,1 & Cathepsin & 89 & 0 & 0.4 \\
\hline & hmit-1.1 & Y51A2D.4 & TRA & 1,5 & $\mathrm{H}(+)$ Myoinositol transporters & 90 & 1 & 0.04 \\
\hline & $d r d-100$ & F08A8.2 & LIP & 2,8 & Acyl coenzyme A oxidase & 98 & 5 & 0.29 \\
\hline & $d h s-7$ & E04F6.7 & MIT & 3,3 & Dehydrogenases & 97 & 1 & 0.87 \\
\hline & $d r d-5$ & F55E10.6 & MIT & 4,3 & Dihydroxybenzoate dehydrogenase & 92 & 0 & 0 \\
\hline & $d r d-6$ & F13H8.3 & NAD & 7,7 & Nucleoside hydrolase, & 56 (fly) & 0 & 1 \\
\hline & pcp-3 & $\mathrm{F} 23 \mathrm{~B} 2.11$ & LYS & 3,8 & Serine protease & 41 & 1 & 0.2 \\
\hline & pcp-2 & F23B2.12 & LYS & 18,3 & Lysosomal serine-type peptidase & 35 & 1 & - \\
\hline & $d r d-7$ & K10B2.2 & LYS & 6,7 & Intrinsic/integral to membrane & 98 & 0 & 0 \\
\hline & $d r d-8$ & Y40D12A.2 & LYS & 5,9 & Lysosomal protective protein & 93 & 0 & 0.17 \\
\hline & col-135 & M199.5 & $\mathrm{COL}$ & 1,7 & Collagen alpha-1 & 91 & 0 & - \\
\hline & $d r d-9$ & F18E2.1 & MET & 3 & Purple acid phosphatase & 91 & 0 & 0 \\
\hline & nep-17 & F54F11.2 & MET & 6 & Neprilysin, metallopeptidases & 48 & 2 & 0 \\
\hline & drd-10 & C33G8.3 & AND & 6,7 & Mannosylphosphate transferase & 85 & 0 & 0 \\
\hline & тир-4 & K07D8.1 & AND & 4 & Muscle positioning & 53 & 24 & 0.9 \\
\hline
\end{tabular}

(C48B4.1) or growth regulation (F40F4.6) (Table S7); for instance, the gene that encodes the muscle positioning protein MUP-4 displayed a high degree of interconnectivity with other DR-regulated genes. Seven out of ten interacting genes are part of our gene list (Table S2S4). An additional 14 genes are part of the MUP-4 

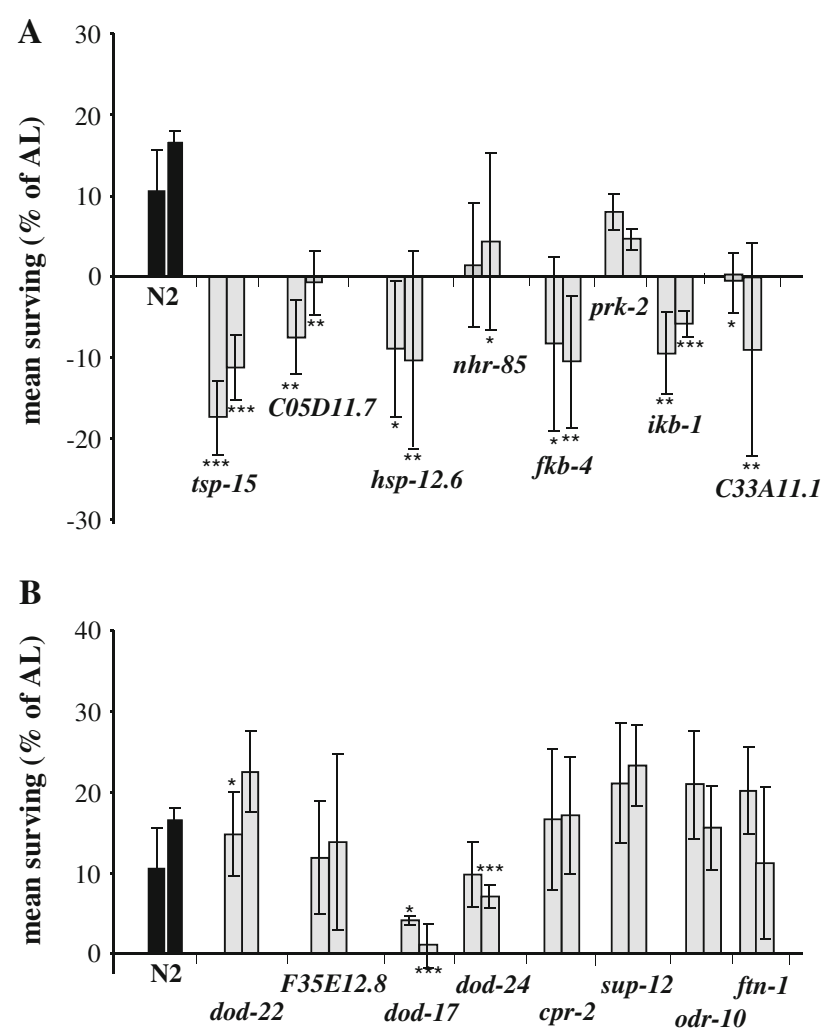

Fig. 2 Survival of selected $C$. elegans mutant strains under heat stress condition $\left(35^{\circ} \mathrm{C}\right)$. Percentage increase in survivorship of severe DR conditions (each right bar) and mild DR conditions (each left bar) over ad libitum conditions. a Mutant strains in which DR-induced heat stress resistance is reduced or abolished; $\mathbf{b}$ mutant strains in which DR-induced heat stress resistance was not abolished

network, indicating that mup-4 functions as a hub gene in the regulation of DR-related processes (Figure S3A). The lysosomal protective gene Y40D12A.2 interconnects with several genes (i.e., kin-2, ftn-l) that have not been described in the context of lysosome function (Figure S3B).

Heat stress resistance and life span of selected

C. elegans mutants grown under ad libitum and dietary restriction conditions

For functional analysis, we chose evolutionarily conserved genes that are consistently up-regulated under DR and searched for appropriate loss of function $C$. elegans mutants from public resources. We tested survival under heat stress in sixteen mutant strains that were grown under moderate DR, stringent DR and AL conditions (Fig. 2, Table S11). Given that DR conditions are frequently associated with enhanced resistance to stress, the thermotolerance assay is appropriate (Lithgow et al. 1994). As previously described (Gerisch et al. 2001), DR-fed N2 wild-type worms show increased resistance to heat stress compared with AL-fed worms. This DR response is abolished in the mutants $h s p .12 .6, f k b-4, i k b-1, \mathrm{C} 05 \mathrm{D} 11.7$, tsp-15 and C33A11.1; in fact, heat resistance in these strains is reduced in DR compared with AL conditions. The other strains show a similar (F35E12.8 and $c p r-2)$, reduced (nhr-85, prk-2, dod-17 and dod-24) or increased (dod-22, odr-10, ftn-1 and sup-12) DR response compared with wild type. Because DR increases life span in several species (Mair and Dillin 2008), this important DR response was analyzed in three selected mutant strains (Fig. 3, Table S12). The mean life span of N2 wild-type worms was increased by approximately $20 \%$ in DR-fed worms compared with AL-fed worms. The increased life span in response to DR is completely abolished in $f k b-4$, dod-22 and $i k b-1$ mutants. This result was obtained under moderate as well as stringent DR conditions.

\section{Discussion}

In this study, we identified 189 genes that are differentially expressed in response to DR. Based on sequence homology, approximately $25 \%$ of these genes are evolutionarily conserved, but their functions are not known. Among this group, 32 genes were also identified using a functional ortholog approach (Meinel et al. 2011), suggesting that the functions of these genes are similar between species. Thus, the 32 identified genes are prime candidates for playing a crucial role in the DR response. Based on this strategy, sixteen genes that are up-regulated in response to DR were tested in C. elegans. We found that eight of these genes are indeed necessary for resistance to heat stress, which is an established DR response (Lithgow et al. 1994). Moreover, three of the genes were identified as necessary for life span extension under DR conditions. Recently, two remarkable analyses have been published in which high-throughput technologies, data mining and sequence comparisons between species were also used to predict the function of uncharacterized genes. By assuming that most biological processes are regulated by protein complexes, Tacutu and colleagues uncovered new genes involved in the regulation of life span by systematically analyzing interacting proteins that are encoded by known longevity genes found in C. elegans and humans (Tacutu et al. 2013). Depuydt and colleagues searched for overlapping sets of $C$. elegans proteins that are differentially expressed in response to DR and in the daf-2 mutant (Depuydt et al. 2013). Similar to the results from our study, both publications revealed novel genes of the DR response by combining bioinformatic approaches with functional assays. Thus, data mining of "-omics" data sets is a useful approach for the detection of as-of-yet unknown key players in fundamental biological processes within and across species. In the future, the increasing availability of mutant strains enabled by the 

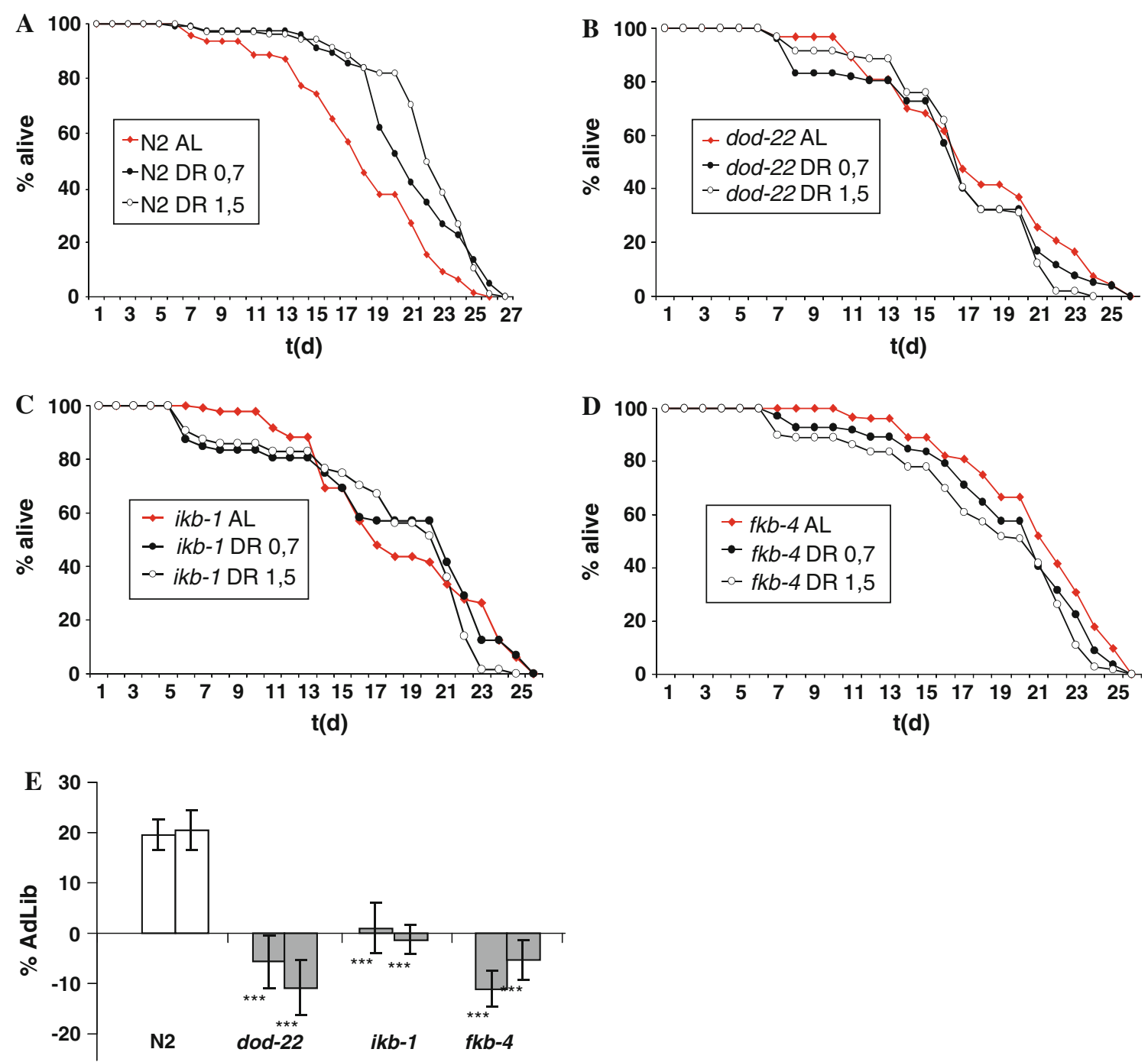

Fig. 3 Life span analysis of selected C. elegans mutant strains under ad libitum (AL) and dietary restriction (DR) conditions; a-d survivorship of worms at $20^{\circ} \mathrm{C}$; e difference in mean life span between $\mathrm{AL}$

million mutation project (Thompson et al. 2013) will facilitate the systematic analysis of a large number of putative functional orthologs in the $C$. elegans model organism. It is also important to mention that the effects of DR on health parameters and gene expression are abolished after 6 months of refeeding in mice (Giller et al. 2013). This has to be taken into account in future studies.

Although cpr-2, odr-10, sup-12 and ftn- 1 are consistently and highly up-regulated in response to DR, DRinduced resistance to heat stress was not abolished in the corresponding mutant strains. It is possible that these genes are necessary for other DR responses, such as reduced brood size (Mair and Dillin 2008) or reduced body size (Palgunow et al. 2012). In line with this, the levels of the predicted DAF-16-interacting protein DAF-22 displayed no changes in response to DR. DR-mediated heat stress

and DR conditions (\% of AL); a N2 wild type, b dod-22(ok1918), c $i k b-1(n r 2027)$, d $f k b-4(o k 240)$, e $\operatorname{dod}-22(o k 1918), i k b-1(n r 2027)$, d $f k b-4(o k 240)$

tolerance was not affected in daf-22 mutants, and increased longevity in response to DR was completely abolished in this mutant. Alternatively, the functions of $c p r-2$, odr-10, sup-12 and $f t n-1$ might be redundant with paralogous genes. For instance, the cytoskeleton protein encoded by the sup-12 gene has 18 paralogs, and the G-protein-coupled receptor encoded by the $o d r-10$ gene has 25 direct paralogs. Thus, functional redundancy of identified DR-responsive genes might explain why functional tests of these genes are not always consistent.

In our analysis of DR-responsive genes, the number of down-regulated genes is higher than the number of upregulated genes (114 versus 75 , respectively). One prominent group of down-regulated genes encodes proteins containing a CUP-like domain and a signal peptide, indicating that these proteins are secreted. Similar genes are 
present in mammals, but their functions are unknown (O'Rourke et al. 2006). The CUB-like domain consists of approximately 130 amino acids and contains two conserved cysteine residues (InterPro). The CUB-like domain is related to the CUB domain, which consists of approximately 110 amino acids and contains four conserved cysteine residues that likely form two disulfide bridges (Bork and Beckmann 1993). In C. elegans, proteins containing the CUP-like domain act in the pathogen and immune response and are predominantly expressed in the intestine and neurons (http://worm-tissue.princeton.edu). They are up-regulated in response to the pathogens $P$. aeruginosa and Y. pestis (Bolz et al. 2010; Cornejo Castro et al. 2010; O'Rourke et al. 2006; Shapira et al. 2006; Troemel et al. 2006). RNAi against genes (dod-24, C17H12.8 and F08G5.6) that encode CUP-like domain-containing proteins resulted in an enhanced susceptibility to pathogens, indicating functions in the immune response. The induction of CUP-like domain-encoded genes by pathogens depends on p38 MAPK (Alper et al. 2007), the intestine-specific GATA transcription factor elt-2 (Shapira et al. 2006) and the phospholipase egl-8 (Kawli et al. 2010). Genes containing the CUB-like domain are also induced by exposure to other stress factors such as X-rays (O'Rourke et al. 2006). So far, the function of CUP-like domain-containing proteins in the DR response is not known. The best-known members of this family are described as "downstream of daf-16" (dod) (Lee et al. 2008; Sakaguchi et al. 2004). Thus, DR-induced down-regulation of genes that encode CUP-like domain-containing proteins might be mediated by the FOXO-like transcription factor DAF-16. Nevertheless, the physiological function of these genes in the DR response remains obscure.

We found eight genes (C05D11.7, nhr-85, prk-2, tsp15, $h s p-12.6, i k b-1, d o d-22$ and $f k b-4)$ that are up-regulated in response to DR and are necessary for the DRinduced resistance to heat stress. Moreover, increased life span in response to DR is abolished in dod-22, ikb-1 and $f k b-4$ mutants. Except for $h s p-12.6$ (Uno et al. 2013), all genes have not been annotated in the context of DR. Interestingly, seven out of eight genes seem to be responsive to certain stress signals such as metabolic stress (dod-22, fkb-4 and $n h r-85)$, DNA damage (ikb-1), heat shock (hsp-12.6) or cancer-like overgrowth (prk-2 and $t s p-15)$. Very recently, the Ruvkun lab discovered the cellular surveillance-activated detoxification and defenses (cSADDs) pathway, which has a central cytoprotective role in the regulation of longevity (Melo and Ruvkun 2012; Shore and Ruvkun 2013; Shore et al. 2012). Here, we propose that most of the identified DR-responsive genes are components of this cSADDs pathway, which is, among others, important for the survival of organisms during food deprivation.
Acknowledgments We thank Astrid Reinke for high-throughput plating and Fabian Neumann for strain processing. This work was supported by a grant from the German Ministry of Education and Science (FD). We also thank the Caenorhabditis Genetics Center (CGC, Minneapolis, USA). Some strains were provided by the CGC, which is funded by the NIH Office of Research Infrastructure Programs (P40 OD01040).

\section{References}

Alper S, McBride SJ, Lackford B, Freedman JH, Schwartz DA (2007) Specificity and complexity of the Caenorhabditis elegans innate immune response. Mol Cell Biol 27(15):5544-5553. doi:10. 1128/MCB.02070-06

Barrett T, Troup DB, Wilhite SE, Ledoux P, Rudnev D, Evangelista C, Kim IF, Soboleva A, Tomashevsky M, Marshall KA, Phillippy KH, Sherman PM, Muertter RN, Edgar R (2009) NCBI GEO: archive for high-throughput functional genomic data. Nucleic Acids Res 37 (Database issue):D885-890. doi:10. 1093/nar/gkn764

Bolz DD, Tenor JL, Aballay A (2010) A conserved PMK-1/p38 MAPK is required in Caenorhabditis elegans tissue-specific immune response to Yersinia pestis infection. J Biol Chem 285(14):10832-10840. doi:10.1074/jbc.M109.091629

Bork P, Beckmann G (1993) The CUB domain. A widespread module in developmentally regulated proteins. $\mathrm{J}$ Mol Biol 231(2):539-545. doi:10.1006/jmbi.1993.1305

Chikina MD, Huttenhower C, Murphy CT, Troyanskaya OG (2009) Global prediction of tissue-specific gene expression and contextdependent gene networks in Caenorhabditis elegans. PLoS Comput Biol 5(6):e1000417. doi:10.1371/journal.pcbi.1000417

Cornejo Castro EM, Waak J, Weber SS, Fiesel FC, Oberhettinger P, Schutz M, Autenrieth IB, Springer W, Kahle PJ (2010) Parkinson's disease-associated DJ-1 modulates innate immunity signaling in Caenorhabditis elegans. J Neural Transm 117(5):599-604. doi:10.1007/s00702-010-0397-4

Depuydt G, Xie F, Petyuk VA, Shanmugam N, Smolders A, Dhondt I, Brewer HM, Camp DG, Smith RD, Braeckman BP (2013) Reduced insulin/IGF-1 signaling and dietary restriction inhibit translation but preserve muscle mass in Caenorhabditis elegans. Mol Cell Proteomics. doi:10.1074/mcp.M113.027383

Gerisch B, Weitzel C, Kober-Eisermann C, Rottiers V, Antebi A (2001) A hormonal signaling pathway influencing C. elegans metabolism, reproductive development, and life span. Dev Cell 1(6):841-851

Giller K, Huebbe P, Hennig S, Dose J, Pallauf K, Doering F, Rimbach G (2013) Beneficial effects of a 6-month dietary restriction are time-dependently abolished within 2 weeks or 6 months of refeeding-genome-wide transcriptome analysis in mouse liver. Free Radical Biol Med 61C:170-178. doi:10.1016/j.freerad biomed.2013.03.023

Hariri N, Thibault L (2010) High-fat diet-induced obesity in animal models. Nutr Res Rev 23(2):270-299. doi:10.1017/S0954422 410000168

Hirabayashi S, Baranski TJ, Cagan RL (2013) Transformed drosophila cells evade diet-mediated insulin resistance through wingless signaling. Cell 154(3):664-675. doi:10.1016/j.cell.2013.06.030

Honjoh S, Yamamoto T, Uno M, Nishida E (2009) Signalling through RHEB-1 mediates intermittent fasting-induced longevity in C. elegans. Nature 457(7230):726-730. doi:10.1038/nature07583

Kahn SE, Hull RL, Utzschneider KM (2006) Mechanisms linking obesity to insulin resistance and type 2 diabetes. Nature 444(7121):840-846. doi:10.1038/nature05482 
Kawli T, Wu C, Tan MW (2010) Systemic and cell intrinsic roles of Gqalpha signaling in the regulation of innate immunity, oxidative stress, and longevity in Caenorhabditis elegans. Proc Natl Acad Sci USA 107(31):13788-13793. doi:10.1073/pnas. 0914715107

Kenyon CJ (2010) The genetics of ageing. Nature 464(7288): 504-512. doi:10.1038/nature08980

Kenyon C, Chang J, Gensch E, Rudner A, Tabtiang R (1993) A $C$. elegans mutant that lives twice as long as wild type. Nature 366(6454):461-464. doi:10.1038/366461a0

Lee JM, Takahashi M, Mon H, Mitsunobu H, Koga K, Kawaguchi Y, Nakajima Y, Kusakabe T (2008) Construction of gene expression systems in insect cell lines using promoters from the silkworm Bombyx mori. J Biotechnol 133(1):9-17. doi:10.1016/ j.jbiotec.2007.08.033

Li S, Armstrong CM, Bertin N, Ge H, Milstein S, Boxem M, Vidalain PO, Han JD, Chesneau A, Hao T, Goldberg DS, Li N, Martinez M, Rual JF, Lamesch P, Xu L, Tewari M, Wong SL, Zhang LV, Berriz GF, Jacotot L, Vaglio P, Reboul J, Hirozane-Kishikawa T, Li Q, Gabel HW, Elewa A, Baumgartner B, Rose DJ, Yu H, Bosak S, Sequerra R, Fraser A, Mango SE, Saxton WM, Strome S, Van Den Heuvel S, Piano F, Vandenhaute J, Sardet C, Gerstein M, Doucette-Stamm L, Gunsalus KC, Harper JW, Cusick ME, Roth FP, DE Hill, Vidal M (2004) A map of the interactome network of the metazoan $C$. elegans. Science 303(5657):540-543. doi:10.1126/science.1091403

Lithgow GJ, White TM, Hinerfeld DA, Johnson TE (1994) Thermotolerance of a long-lived mutant of Caenorhabditis elegans. J Gerontol 49(6):B270-B276

Mair W, Dillin A (2008) Aging and survival: the genetics of life span extension by dietary restriction. Ann Rev Biochem 77:727-754. doi:10.1146/annurev.biochem.77.061206.171059

Meinel T, Schweiger MR, Ludewig AH, Chenna R, Krobitsch S, Herwig R (2011) Ortho2ExpressMatrix-a web server that interprets cross-species gene expression data by gene family information. BMC Genomics 12:483. doi:10.1186/1471-2164$12-483$

Melo JA, Ruvkun G (2012) Inactivation of conserved C. elegans genes engages pathogen- and xenobiotic-associated defenses. Cell 149(2):452-466. doi:10.1016/j.cell.2012.02.050

O'Rourke D, Baban D, Demidova M, Mott R, Hodgkin J (2006) Genomic clusters, putative pathogen recognition molecules, and antimicrobial genes are induced by infection of $C$. elegans with M. nematophilum. Genome Res 16(8):1005-1016. doi:10.1101/ gr.50823006

Palgunow D, Klapper M, Doring F (2012) Dietary restriction during development enlarges intestinal and hypodermal lipid droplets in Caenorhabditis elegans. PLoS One 7(11):e46198. doi:10.1371/ journal.pone.0046198

Parkinson H, Kapushesky M, Kolesnikov N, Rustici G, Shojatalab M, Abeygunawardena N, Berube H, Dylag M, Emam I, Farne A, Holloway E, Lukk M, Malone J, Mani R, Pilicheva E, Rayner TF, Rezwan F, Sharma A, Williams E, Bradley XZ, Adamusiak T, Brandizi M, Burdett T, Coulson R, Krestyaninova M, Kurnosov P, Maguire E, Neogi SG, Rocca-Serra P, Sansone SA, Sklyar N, Zhao M, Sarkans U, Brazma A (2009) ArrayExpress update-from an archive of functional genomics experiments to the atlas of gene expression. Nucleic Acids Res 37 (Database issue):D868-872. doi:10.1093/nar/gkn889

Pungaliya C, Srinivasan J, Fox BW, Malik RU, Ludewig AH, Sternberg PW, Schroeder FC (2009) A shortcut to identifying small molecule signals that regulate behavior and development in Caenorhabditis elegans. Proc Natl Acad Sci USA 106(19):7708-7713. doi:10.1073/pnas.0811918106

Sakaguchi A, Matsumoto K, Hisamoto N (2004) Roles of MAP kinase cascades in Caenorhabditis elegans. $\mathrm{J}$ Biochem 136(1):7-11. doi:10.1093/jb/mvh097

Shapira M, Hamlin BJ, Rong J, Chen K, Ronen M, Tan MW (2006) A conserved role for a GATA transcription factor in regulating epithelial innate immune responses. Proc Natl Acad Sci USA 103(38):14086-14091. doi:10.1073/pnas.0603424103

Shore DE, Ruvkun G (2013) A cytoprotective perspective on longevity regulation. Trends Cell Biol 23(9):409-420. doi:10. 1016/j.tcb.2013.04.007

Shore DE, Carr CE, Ruvkun G (2012) Induction of cytoprotective pathways is central to the extension of lifespan conferred by multiple longevity pathways. PLoS Genet 8(7):e1002792. doi:10.1371/journal.pgen.1002792

Smith GP, Petrenko VA (1997) Phage display. Chem Rev 97(2): 391-410

Swindell WR (2008) Genes regulated by caloric restriction have unique roles within transcriptional networks. Mech Ageing Dev 129(10):580-592. doi:10.1016/j.mad.2008.06.001

Szewczyk NJ, Udranszky IA, Kozak E, Sunga J, Kim SK, Jacobson LA, Conley CA (2006) Delayed development and lifespan extension as features of metabolic lifestyle alteration in $C$. elegans under dietary restriction. J Exp Biol 209(Pt 20):4129-4139. doi:10.1242/jeb.02492

Tacutu R, Craig T, Budovsky A, Wuttke D, Lehmann G, Taranukha D, Costa J, Fraifeld VE, de Magalhaes JP (2013) Human ageing genomic resources: integrated databases and tools for the biology and genetics of ageing. Nucleic Acids Res 41 (Database issue):D1027-1033. doi:10.1093/nar/gks1155

Tain LS, Lozano E, Saez AG, Leroi AM (2008) Dietary regulation of hypodermal polyploidization in C. elegans. BMC Dev Biol 8:28. doi:10.1186/1471-213X-8-28

Thompson O, Edgley M, Strasbourger P, Flibotte S, Ewing B, Adair R, Au V, Chaudhry I, Fernando L, Hutter H, Kieffer A, Lau J, Lee N, Miller A, Raymant G, Shen B, Shendure J, Taylor J, Turner EH, Hillier LW, Moerman DG, Waterston RH (2013) The million mutation project: a new approach to genetics in Caenorhabditis elegans. Genome Res 23(10):1749-1762. doi:10.1101/gr.157651.113

Tissenbaum HA, Guarente L (2001) Increased dosage of a sir-2 gene extends lifespan in Caenorhabditis elegans. Nature 410(6825): 227-230. doi:10.1038/35065638

Troemel ER, Chu SW, Reinke V, Lee SS, Ausubel FM, Kim DH (2006) p38 MAPK regulates expression of immune response genes and contributes to longevity in C. elegans. PLoS Genet 2(11):e183. doi:10.1371/journal.pgen.0020183

Uno T, Sakamoto K, Isoyama Y, Hiragaki S, Uno Y, Kanamaru K, Yamagata H, Takagi M, Mizoguchi A, Takeda M (2013) Relationship between the expression of Rab family GTPases and neuropeptide hormones in the brain of Bombyx mori. Histochem Cell Biol 139(2):299-308. doi:10.1007/s00418-012-1021-5

Van Gaal LF, Mertens IL, De Block CE (2006) Mechanisms linking obesity with cardiovascular disease. Nature 444(7121):875-880. doi:10.1038/nature05487

Weindruch R, Naylor PH, Goldstein AL, Walford RL (1988) Influences of aging and dietary restriction on serum thymosin alpha 1 levels in mice. J Gerontol 43(2):B40-B42 